\title{
Movimientos estudiantiles en América Latina: Ciclos de sincronía y desencuentros*
}

\section{Resumen}

El texto tiene como objeto visualizar a grandes rasgos los diferentes ciclos que han conformado la historia de las organizaciones estudiantiles desde fines del siglo XIX hasta la primera década de la presente centuria. El escrito se concentra en las universidades consideradas emblemáticas de cinco países, así se tiene de norte a sur a la Universidad Nacional Autónoma de México -UNAM-, la Universidad de San Carlos -USAC, la Universidad Nacional Autónoma de Nicaragua -UNAN-, la Universidad Central del Ecuador -UCE- y a la Universidad de Buenos Aires -UBA-. ${ }^{1}$ La intención del artículo radica en mostrar cómo los distintos periodos organizativos poseen ciclos de sincronía entre sí a pesar de todas las diferencias sociales, políticas y económicas que configuran la historia de cada país. También se evidencia cómo desde inicios de la década de los ochenta esta simetría se rompe y las universidades analizadas adquiere un derrotero diferente en términos de organización y movilización estudiantiles.

Palabras clave: Movimientos estudiantiles, ciclos, universidad, organización.

\section{Abstract}

This research's aim is to broadly visualize the different cycles that characterize the history of student movements, from the end of the XIX century to the first decade of this century. To this end, I analyze the most important universities in five Latin American countries, namely, the National Autonomous University of Mexico -UNAM (Spanish acronym)-, the San Carlos -USAC (Spanish acronym)-, the National Autonomous University of Nicaragua -UNAN (Spanish acronym)-, the Central University of Ecuador -UCE (Spanish acronym)-, and the University of Buenos Aires-UBA (Spanish acronym)-, ordered from North to South, respectively. This article shows how different organizing periods have synchronic cycles despite of the social, politic and economic differences that characterize each country's history. This research also describes how, at the beginning of the 80 s decade, this symmetry falls apart and each university takes a different path in relation to its student organization and forms of mobilization.

Keywords: student movements, cycles, university, organization

POR CARLOS CELI HIDALGO, candidato a Doctor en Estudios Latinoamericanos por la UNAM, Maestro en Estudios Latinoamericanos por la UASB -Universidad Andina Simón Bolívar- de Quito. Ha sido profesor en las carreras de Sociología y Comunicación Social en la UCE -Universidad Central del Ecuador- en la PUCE -Pontificia Universidad Católica del Ecuador-y profesor de asignatura en la FCPyS de la UNAM. Las líneas de trabajo en las que se desempeña son: historia de las juventudes, historia de los movimientos estudiantiles en América Latina, teorías de la representación y la imagen, antropología de la vida cotidiana. carlos.celi.h@gmail.com

* Buena parte del texto se desprende de la investigación realizada para la tesis doctoral titulada "Movimientos juveniles: cambios y permanencias en las formas organizativas de los movimientos estudiantiles universitarios en América Latina”, del programa de Estudios Latinoamericanos de la UNAM. 


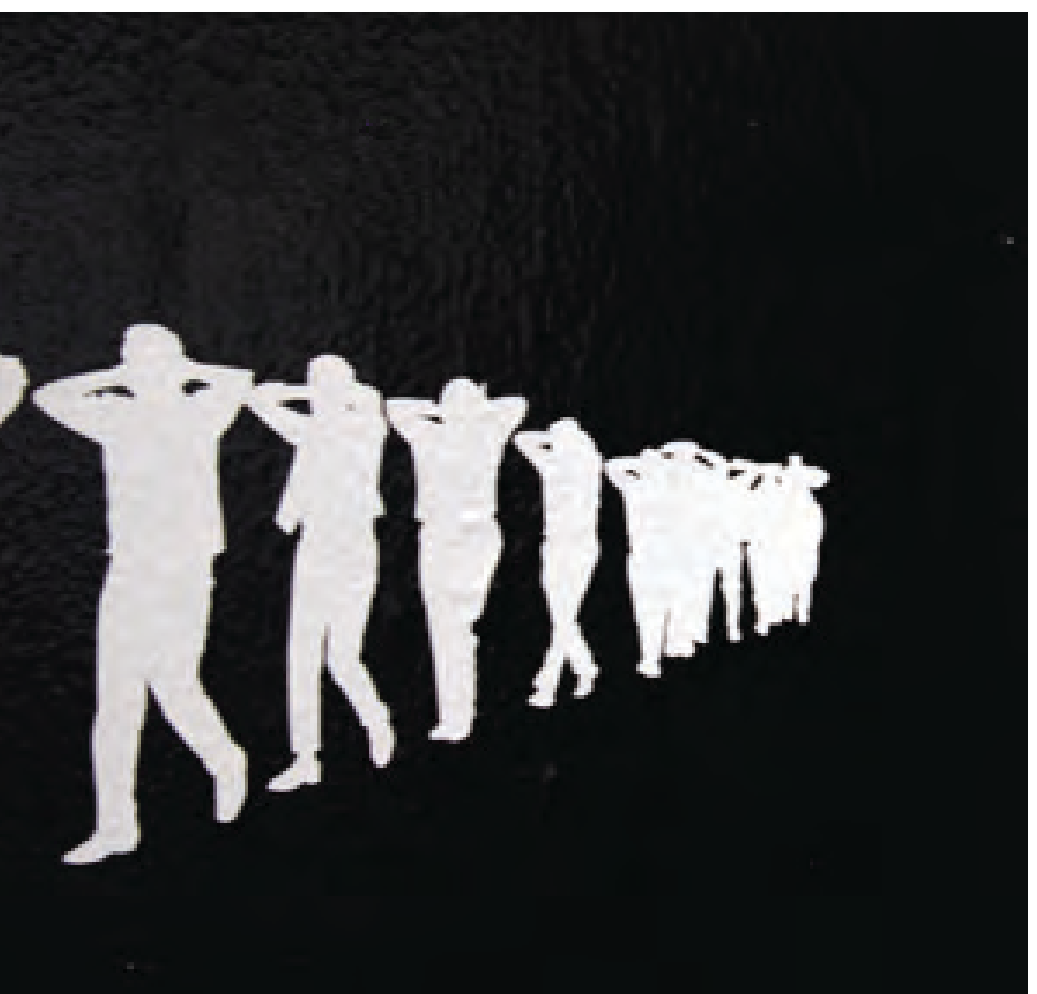

Yohnattan Mignot (Uruguay), Sin título, fotografía intervenida, 2018 / Archivo Histórico de la UNAM / IISUE-AHUNAM

\section{Resumo}

O objetivo do texto é visualizar amplamente os diferentes ciclos que moldaram a história das organizações estudantis do final do século XIX até a primeira década do presente século. O documento coloca ênfase as universidades consideradas emblemáticas de cinco países, de norte a sul, da Universidade Nacional Autônoma do México -UNAM- a Universidade de San Carlos -USAC- a Universidade Nacional Autônoma da Nicarágua -UNAN-. A Universidade Central do Equador -UCE- e a Universidade de Buenos Aires -UBA-. A intenção do artigo é mostrar como os diferentes períodos organizacionais têm ciclos de sincronia entre si, apesar de todas as diferenças sociais, políticas e econômicas que compõem a história de cada país. Também é evidente que desde o início dos anos oitenta esta simetria se quebra e cada uma das universidades analisadas adquire um caminho diferente em termos de organização e mobilização estudantil.

Palabras chave: movimentos estudantis, ciclos, universidade, organização

\section{Modernidad periférica, Estado y Universidad}

Los movimientos estudiantiles así como sus formas organizativas fueron y son producto de las distintas épocas en las que han estado presentes, a la vez que alteran los regímenes e instituciones con quienes tienen conflicto, aunque también con los que coinciden y se solidarizan.

En la medida en que se separaron las relaciones entre Iglesia y Estado, las universidades a su vez permitieron el paso a nuevas ideas en las que lentamente se fue instalando una concepción moderna ligada al saber y al ingreso del capitalismo en la cotidianidad, claro que dicho paso fue exclusivo y excluyente para beneficio de unas minorías en las que se reservaba su ingreso a las mismas en función de su procedencia de clase y raza, pero que de a poco y debido a la ampliación y complejización del estado, así como de un mayor requerimiento de mano de obra calificada se incrementó el acceso de otros grupos sociales a la par que contribuyó de modo asimétrico y desigual a la formación de un sector poblacional conocido genéricamente como clases medias. Sin embargo, la misma lógica de la universidad se encargaba de reproducir y magnificar la distancia existente entre letrados $\mathrm{y}$ analfabetas, quienes para principios del siglo XX eran mayoría, así como tampoco dejaba de mostrar las bondades de la "cultura legítima" promulgada por la institución, encargada además de evidenciar los privilegios de acceder a la vida moderna.

Claro que la modernidad era periférica y dependiente para el caso de América Latina, donde distintas velocidades y modos de vida coexisten de manera heterogénea y en la que el estado difícilmente lograba administrar estas diferencias que en todo caso confluían en las ciudades y en las cuales no coincidencialmente se asentaban las universidades, mismas que a su vez todavía tenían serios conflictos entre los distintos tipos de saber que ahí convergían, aunque de a poco el pensamiento escolástico y eclesial fue retrocediendo para dar paso al positivismo y al humanismo insertos ya en el siglo XX.

Si bien la universidad como institución no es hija del siglo XX ni de la modernidad, esta se tuvo que adaptar de modo dramático para poder subsistir como 
entidad que regula el saber a la vez que acoplarse a los cambios producidos por el enfrentamiento finisecular entre liberales y conservadores, donde a la postre serán los liberales quienes impongan su modo de ver las cosas y de articular el Estado al mercado, así como de intentar instaurar la educación laica y ampliar la noción de ciudadanía como de participación política, esto sin duda constituyó un modo de ser estudiantil que los vuelve hijos del siglo XX y como tales tuvieron que coexistir con las transformaciones del llamado siglo corto en cuanto a la construcción de la matriz estadocéntrica, expansión de los partidos políticos, la urbanización paulatina y participación en la transformación de la universidad hacia algo más acorde con los requerimientos del nuevo siglo.

Por su parte la universidad como institución se desenvuelve en un entramado histórico y como tal ha atravesado por distintos periodos en tanto formadora de las élites y de las masas, siendo a la vez productora y reproductora de conocimientos técnicos con pretensiones de neutralidad o de saberes comprometidos con lo social, guarida de radicales o de estudiantes sin postura política, por tanto para hablar de ella es necesario contextualizarla histórica y políticamente en función de sus actores y de lo que de ella se quiere observar. Esta a su vez aglutina estudiantes, quienes son su razón de ser, tiene un papel formativo y es caja de resonancia de los problemas sociales, pero además sirve para diferenciar a quienes acceden a ella, conjuga en su interior a una minoría que comparte tiempos, espacios y rituales, a lo cual se suma su alta rotatividad, en esa medida se construye un modo de ser estudiante.

Hasta cierto punto están dotados de homogeneidad entre sí, por lo menos en determinadas épocas y en cuanto a universidades públicas de las ciudades capitalinas se refiere, lo cual permite la puesta en juego de ciertas sensibilidades en común. La universidad para funcionar tiene sus normas y modos de gobierno que permiten en mayor o menor medida la participación estudiantil y posee una autonomía que le posibilita cierta independencia. Tanto las formas de gobierno universitario como la autonomía han sido motivo de pugnas interminables a lo largo del siglo y en ambos casos están dotadas de una significación e interpretación política que debe ser analizada concretamente para poder entender los cambios y modos de partici- pación del estudiantado, pues las repercusiones de las transformaciones institucionales no son menores a la hora de entender la situación organizativa estudiantil universitaria.

No sobra resaltar que para el desarrollo de las organizaciones estudiantiles fue necesario el "desenvolvimiento de las instituciones sociales y políticas que les den sustento institucional, sino que el propio desarrollo de las ideas y las instituciones -para el caso de la Universidad- definieron un tipo de estudiante y de maneras de manifestación política del mismo" (194) esgrime Álvarez, y prosigue "para la constitución del movimiento estudiantil y su inserción en el imaginario social fueron necesarias, no sólo instituciones de educación superior aptas para ello, sino un espacio intelectual, un cúmulo de ideas que lo refuercen, valoren y estimulen", (2002a: 194). Esto aclararía el por qué desde la estabilización de ciertas entidades es que surgieron distintas maneras de organizarse estudiantilmente como el hecho de que puedan ser llamados modernos ya que descollaron a la par de una concepción de Estado y la política manifestada en la configuración de cierto tipo de partidos políticos.

Sumando a esto el sentido de época imperante y al cual se lo entiende como la miríada de situaciones sociales y culturales que suman distintas manifestaciones y oscilaciones de lo político/la política, configurando un todo interpretativo que se retroalimenta tanto de lo que ocurre como de lo que se cree que ocurre en otras partes, a la vez de lo que pasa localmente; posee pretensiones conjugadas y simultáneas efecto de una mutua incorporación de sentires, símbolos y acciones, dándose un juego de espejos que multiplica el efecto de la creencia, generando marcos internacionales de identificación masiva con respecto a distintos temas.

Esto facilita aclarar el por qué en entornos diferentes surgen maneras de organizarse relativamente similares con posturas no tan distantes, con sus especificidades claro; sin embargo, se intenta recalcar las constantes que adquieren el sentido de las organizaciones, su para qué, con quiénes y contra quiénes, además de la sincronía, diacronía y conjugación relativas que permitieron observar la ondulación de las organizaciones estudiantiles, sus avances y retrocesos y como solo a partir de los años ochenta es que este paralelismo se empieza a fracturar. 


\section{Conformación y expansión}

Para la última década del siglo XIX y primeros años del nuevo siglo, se conformaron clubes políticos en su mayoría liberales y conservadores, así también se crearon agrupaciones gremiales por carrera, sociedades literarias o ateneos que en buena parte desembocaron en los partidos políticos. La procedencia estudiantil en su mayoría era desde las élites y su posición política alternaba entre el liberalismo y el conservadurismo.

De a poco se fundan las federaciones estudiantiles. Así se tiene la Federación Universitaria de Buenos Aires -FUBA- (1908), la Asociación de Estudiantes Universitarios -AEU- (1920) y la Federación Estudiantil Mexicana -FEM- (1920), en Argentina, Guatemala y México respectivamente. En todos los casos presionarán por estar en el gobierno de la universidad, así como se conseguirá las respectivas autonomías universitarias, en cada ocasión hay retrocesos y avances con disoluciones o restricciones, todo esto dará motivo para distintos tipos de acciones con el afán de que se restituyan, ya sea frente al gobierno de la universidad o en conjunto frente al Estado central.

De modo simultáneo se dieron una serie de congresos regionales y continentales en los que se apostaba tanto al unionismo centroamericano como al latinoamericanismo. En general a este primer momento se lo llama de conformación y discurre desde fines del siglo XIX y prosigue a lo largo de la década del veinte.

Este primer momento de conformación estudiantil hizo que los partidos políticos tuvieran a lar organizaciones en buena medida bajo su ala, de tal modo las federaciones salen a la luz con la estructura de los partidos, quienes a su vez tienden a remitirse a la articulación administrativa del Estado siguiendo a Duverger (2012: 70).

La presencia de la izquierda en las universidades aún será limitada y en México esta se intentará impulsar desde el Estado con magros resultados. Estarán además los católicos, también habrá posturas de derecha extrema y nacional progresistas. Mientras que en algunos casos las federaciones se consolidan, en otros apenas se crean como la Federación de Estudiantes Universitarios del Ecuador -FEUE- (1942) en Ecuador y el Centro Universitario de la Universidad Nacional -CUUN- (1947) en Nicaragua.
Las posturas estudiantiles en la vida política eran diferenciadas e iban desde el antagonismo con Perón en el caso argentino, la adhesión a Velasco Ibarra en el ecuatoriano, la caída del dictador Ubico en Guatemala, a su vez se asiste a las primeras muestras de oposición al somocismo en Nicaragua, y México se concurre a la consolidación del partido único.

En la UNAM se pasaba de la participación en el gobierno universitario, representada en las academias docente-estudiantiles, a la constricción de la misma desde 1945. La presencia de la derecha o de los partidos oficiales todavía era muy marcada, aunque de a poco se iban desplazando. Además de los gremios por carrera se tuvo una mayor presencia federada, la injerencia partidista tendió a crecer y hubo unos pocos frentes y ligas estudiantiles. A este segundo periodo se denomina de expansión, transcurre a lo largo de la década de los años treinta hasta mediados de los cuarenta.

\section{Años de radicalización...}

Los estudiantes se opusieron constantemente a la gestión de Perón durante su mandato, debido a su afán de intervención en la Universidad que a la vez cuestionaba la lucha reformista, abarcando para el momento a radicales de la Unión Cívica Radical -UCR., liberales, comunistas y socialistas; y también porque tildaban al régimen de populista. No obstante, luego de su caída en 1955 hay un lento acercamiento a los sindicatos que eran bastión peronista, además de un incremento de las posturas humanistas. A Principios de la década de los sesenta se tiene una paulatina radicalización tanto por izquierda como por derecha.

A lo largo de la década de los cincuenta la presencia de un rector de izquierda en la UCE facilita un sostenido posicionamiento del estudiantado, ya para 1960 se tiene un aparecimiento infructuoso de algunas guerrillas y hacia 1963 una nueva dictadura intentará frenar el giro a la izquierda por parte de la sociedad.

Hacia 1954 los años de gestión progresista en Guatemala culminan con una relativa indiferencia y derechización estudiantil que acusaba de comunista al gobierno, aunque luego del golpe militar se tiene un giro a la izquierda por parte del estudiantado. Ya en 1962 se producen unas masivas jornadas de mo- 
vilización estudiantil que sin lograr defenestrar a la dictadura marcaron un fuerte posicionamiento como actores sociales.

Los primeros años del somocismo habían dejado impávidos a los estudiantes, será para mediados de los años cincuenta, junto con exiliados y grupos que reclaman libertad para los presos políticos que se forman pequeños grupos de oposición. Es en 1958 cuando se consigue la autonomía universitaria que habrá mayor libertad organizativa al interno, irrumpen los primeros grupos insurgentes que influirán en el ascenso de la oposición al somocismo. Hacia 1962 se forma el Frente Estudiantil Revolucionario -FER- que surge como agrupación universitaria muy cercana al Frente Sandinista de Liberación Nacional-FSLN- que aparece para 1963.

Durante la década de los cincuenta la UNAM irá en sentido inverso de lo que ocurría en la región, sus federaciones y sociedades de alumnos se adherían al régimen, la izquierda por su parte se movía periféricamente, aunque ya para la siguiente década tendrá una mayor presencia, desplazando al oficialismo sobre todo en las facultades más politizadas que se fueron poblando de pequeños colectivos y arrinconando a las poco legítimas federaciones. En 1966 al calor de una huelga se termina con este largo periodo de conservadurismo, oficialismo y anticomunismo, dando paso a la lógica asamblearia.

\section{...e insurrección}

El punto de inflexión lo marcará la llamada nueva izquierda que surgía más que nada en oposición al Partido Comunista -PC- o a la izquierda electoral y que se dará a partir de la fractura en las relaciones chino-soviéticas por un lado, y por otro, el hecho de que el triunfo de la revolución cubana reposicionaba a la revolución socialista por la vía armada, a esto habría que sumarle toda la corriente contracultural que se desplegó en esos años. Dicha nueva izquierda demandaba más dinamismo y menos burocratización, verticalidad y autoritarismo, además se cuestionaba el apego a las leyes consideradas burguesas por parte de la izquierda tradicional. La izquierda llamada tradicional se defendía cuestionando el radicalismo, aventurerismo e infantilismo. En general se tiene una crítica a determinadas forma del ejercicio de la política 
y a las maneras de entender lo organizacional. Estos enfrentamientos no son menores y darán lugar a múltiples conflictos entre el estudiantado a lo largo de la década del sesenta y parte de los setenta.

En la UNAM además de conformarse los comités de lucha en las facultades y pese a sus múltiples conflictos se dieron a la tarea de agruparse por bloques y frentes, así el Consejo Nacional de Huelga-CNH- logró aglutinar a una inmensa miríada de colectivos en la pugna por exigir una mayor democratización social que se increpaba al gobierno de partido único. Esta manera asamblearia de organización no tendrá marcha atrás en lo que a la UNAM se refiere.

Luego de la masacre de 1968 y para 1971 todavía se conformará el Comité Coordinador de Comités de Lucha-CoCo- que agrupaba a los comités de lucha, pero se dará otro momento represivo denominado el Halconazo y vendrá un significativo repliegue estudiantil hacia las facultades, los barrios, sindicatos y unos pocos en guerrillas, además del interminable enfrentamiento entre colectivos que durará varios años.

Se podría afirmar que este ciclo en la UNAM se agota poco después de 1971, sin embargo, los colectivos organizados no dejaron de moverse durante este tiempo, sin mayor trascendencia en tanto estudiantes pero tendiendo redes y aunque con mucha conflictividad interna no dejaron de activar durante el resto de la década.

El estudiantado de la USAC guatemalteca dejará de ser el centro de la movilización social y de a poco la idea de lucha armada se irá posicionando en las aulas, por otra parte se dieron a la tarea de intentar modificar sus programas de estudio de los cuales exigían compromiso social.

Se desata una escalada de violencia por parte del régimen castrense que fue persistente a lo largo de la década del setenta, esto en un primer momento hizo que se tienda a la radicalización, a la vez que el cambio en los estatutos de la AEU obligó a la conformación de bloques como FRENTE y el FERG, además la lucha social empujaba a participar en frentes de masas y coordinadoras. No obstante, luego de la arremetida represiva hubo un repliegue. Como producto de la fusión de diversos grupos armados -FAR, EGP, ORPA y luego el PGT-, para 1982 se conforma la Unión Revolucionaria Nacional Guatemalteca -URNG-. 
En Nicaragua resultaba imprescindible hacerse del CUUN con el ánimo de generar una correa de transmisión entre los estudiantes y el FSLN quien inicia acciones armadas en 1967 con resultados adversos, esto le obligará a replegarse hasta 1974 para dividirse al año siguiente en tres tendencias: la de la GPP o maoísta, la Proletaria y la Tercerista, todo esto le pasará factura a la organización estudiantil. Por su parte, el somocismo se daba a la tarea de reprimir a la izquierda como a la derecha, lo cual le valió una oposición multilateral. A partir de 1978 se vuelve a dar un ascenso de la lucha social y con ello la reunificación del FSLN, tras acciones armadas y de movilización masiva se produce un asedio que causa la caída del somocismo donde el papel del estudiantado fue decisivo.

A lo largo de la década los sesenta hubo una arremetida militar en la UCE y en general en las universidades públicas ecuatorianas, alternándose con un rico escenario cultural contestatario, además del surgimiento de guerrillas con poco arraigo y las fracturas de la izquierda. Hacia 1969 se funda el Frente Revolucionario de Izquierda Universitaria -FRIU- de línea maoísta, quienes para 1975 pasarán a controlar la FEUE. En general hay mucha agitación social, tomas de tierras, huelgas sindicales, esto sobre todo para la década de los setenta hará que los estudiantes pasen a segundo plano, debido también a que el FRIU no poseía mayor proyecto que no sea el formar cuadros para el Partido Comunista Marxista Leninista del Ecuador -PCMLE-, y que en conjunto provocarán la pérdida de beligerancia estudiantil. Hacia 1979 se produce el regreso a la democracia.

Durante los años sesenta en Argentina se alternará entre democracia y dictadura, los estudiantes se acercaban a los sindicatos, a la par que se movilizaban por presupuesto. A fines de la década se posicionan grupos peronistas tanto de derecha como de izquierda, se forman coordinadoras para empatar con los colectivos de izquierda puesto que los peronistas veían con malos ojos al reformismo y para lo cual se organizaban en mesas de tendencias, aparte de las federaciones y centros de estudiantes.

Los llamados "azos" que fueron asonadas en distintas ciudades del país y tuvieron un carácter casi de insurgencia, varios de estos, tuvieron su origen en las universidades y se produjeron entre 1968 y 1872 . El reclamo por el cupo de ingreso dio lugar a la formación de cuerpos de delegados que se organizaban por curso o materia. La FUA se divide en dos y se mantiene así hasta la vuelta del peronismo, con lo cual se da un auge de las organizaciones afines a este en la UBA, pero también su derecha tiene impulso. Se desataca que cuenta con el apoyo de toda la izquierda, sin embargo será repudiada por este y anticipará de algún modo la represión posterior que vendrá con la dictadura.

El activismo estudiantil será llevado por la nueva izquierda dentro de un amplio marco entre los cuales a grandes rasgos está el guevarismo, maoísmo, trotskismo, los nacionalistas revolucionarios, humanistas y católicos con la teología de la liberación, también hay una mayor presencia de grupos armados y, aunque las conflictos no eran menores entre ellos, se fraguan instancias de coordinación que dan lugar a frentes, bloques, coaliciones, coordinadoras, consejos, con otros sectores sociales.

A diferencia de la UNAM que luego de 1971 se produce un repliegue radicalizado y sin incidencia social y en la UCE que se da una lateralización paulatina, tanto en la USAC como en la UBA la arremetida estudiantil solo pudo ser frenada con regímenes represivos, la UNAN en cambio entrará en una fase revolucionaria.

En la UNAM además de conformarse los comités de lucha en las facultades y pese a sus múltiples conflictos se dieron a la tarea de agruparse por bloques y frentes, asi el Consejo Nacional de Huelga - CNH- logró aglutinar a una inmensa miríada de colectivos en la pugna por exigir una mayor democratización

social que se increpaba al gobierno de partido único. Esta manera asamblearia de organización no tendrá marcha atrás en lo que a la UNAM se refiere. 
Se debe tomar en cuenta que las distintas periodicidades resaltadas no obedecen a fases ascendentes, sino que operan de manera pendular con sus respectivos repliegues y acomodo de fuerzas, en donde de a poco se produce un incremento tanto de agrupaciones como de modos de organizarse. No obstante, desde fines de los años setenta los derroteros en común tienden a desdibujarse y a adquirir contornos particulares en cada uno de los países destacados.

\section{Los años ochenta o el fin de la sincronía}

La organización estudiantil en la UNAM desde mediados de los años ochenta adquiere una tónica de hechos episódicos con mucho despliegue, seguido de conflictos circunscritos en su mayoría al ámbito académico, con grandes periodos donde algunos colectivos se movilizan en las facultades más politizadas.

Se produce un cambio en el eje de las protestas: de la ampliación de las libertades democráticas se pasaría a cuestionar el tipo de intervención estatal en lo educativo. Esto se produce en un contexto de crisis económica y privatización neoliberal, así las maneras de organizarse usadas en el Consejo Estudiantil Universitario -CEU- (1986-7) y en el Consejo General de Huelga -CGH- (1999-2000) recurrieron a la dinámica asamblearia constituida por asambleas en cada escuela, comisiones, brigadas, corrientes políticas disputando el liderazgo, voceros y la plenaria de la cual salen los resolutivos, de menos a más se impugnó la dinámica del liderazgo basada en la representatividad permanente.

\section{La organización estudiantil en la UNAM desde mediados de los años ochenta adquiere una tónica de hechos episódicos con mucho despliegue, seguido de conflictos circunscritos en su mayoría al ámbito académico, con grandes periodos donde algunos colectivos se movilizan en las facultades más politizadas.}

Con el aparecimiento del Ejército Zapatista de Liberación Nacional -EZLN- desde 1994 este influirá todavía más en el cuestionamiento a la política partidaria. Ya para 1999 tanto la rotatividad como la revocabilidad de los voceros se incluirán en el accionar de las asambleas. La desconfianza madurada desde 1968 se expresó en una huelga de más de nueve meses con la toma de los espacios físicos de la UNAM y donde hubo todo un laboratorio de convivencia social. Vistos en el largo plazo se podría decir que los conflictos dieron como resultado un triunfo amargo en los que se impidió el paso a la privatización abierta de la entidad.

En un contexto preelectoral para el 2012 surge el \#YoSoy132 sin tener como eje aglutinador a la UNAM ni demandas académicas, sino de cuestionamiento al tipo de democracia vivida, su manera de movilizarse tuvo arraigo en las Redes Sociales del Internet. Esto cuestionó la misma noción de asamblea al reducir al mínimo el debate presencial, operando en buena medida una dinámica autonómica en términos decisionales así como una descentralización basada en lo operativo más que en la discusión. Este ciclo y del cual no se ha salido se lo remarca como de activismo intermitente.

A mediados de los años ochenta la democracia vuelve a ser parte de la vida política en Guatemala, luego de lo cual disminuirá el flujo de sangre al que se había sometido a la sociedad durante los años setenta y en el cual los universitarios fueron invitados de honor. Los estudiantes por su parte trataban de reorganizarse a través de la AEU y en colectivos de DD.HH.

Las facciones de la URNG no dejaban de intentar controlar a los gremios estudiantiles, producían un efecto inversamente proporcional en cuanto a participación estudiantil se refiere alejándolos del activismo, además de los cruentos embates represivos que todavía se dieron para finales de los ochenta. Para la siguiente década y hacia mediados de la misma se dará la firma de la paz con la URNG.

En cuanto a lo gremial un grupo gansgsteril se hacía de la dirección de la AEU, abocado a negocios de variada índole, contando además con el apoyo de las autoridades universitarias que de algún modo habían convertido a la USAC en un botín político debido a su participación en áreas estratégicas del Estado y a su consolidación como ente rector de la educación superior en el país. 
y la relación entre la UNEN y el gobierno-partidoestado son prácticamente sinónimos. Los periodos de organización estudiantil se dividen en tres momentos: el revolucionario, el segundo de resistencia y el tercero de burocratización, con una fuerte dependencia al partido en todos ellos.

El retorno a la democracia en Ecuador también conlleva varios intentos de privatización y reducción del estado, esto generó una masiva respuesta sindical a lo largo de los años ochenta. Lo propio ocurrirá con la asfixia presupuestaria a la que se quería someter a la UCE, a esto se suma el que fueran apareciendo otras guerrillas que en buena medida habían salido de las universidades, además del apuntalamiento del PCMLE y su brazo estudiantil el FRIU que en conjunto servían para remarcar el desprestigio de lo público.

Con esto se conseguía alejar a los colectivos contestatarios por fuera de la UCE siendo varios de ellos aupados por el surgimiento del movimiento indígena que para inicios de los noventa marcarán el ritmo de las luchas sociales durante casi dos décadas.

La constante en la segunda mitad de los años noventa seguía siendo la privatización, esto generó mucha movilización social en su contra y provocó una caída presidencial en 1997. Aunque hubo una masiva participación estudiantil en dichos sucesos, esta se dio más como parte del clamor general en el movimiento indígena, varios movimientos sociales y "la ciudadanía empoderada" individual serán los protagonistas. En el año 2000 el llamado feriado bancario provocó una migración exorbitante, la economía se dolariza y en conjunto se produce una fuerte oposición que llevó a la renuncia del ejecutivo. Esto se repitió en el 2005 con una concurrida presencia ciudadana y anti organización, que será en parte la que eleve a Correa a la presidencia en el 2007.

Durante este periodo no dejaron de aparecer pequeños colectivos con variadas posturas de izquierda, aglutinados en contra del Tratado de Libre Comercio -TLC- o la salida estadounidense de la base de Manta, que en buena parte serán cobijados por el movimiento indígena. En lo electoral estudiantil algunos se juntaban al calor de las elecciones para asociación-escuela esgrimiendo no tener postura política, el FRIU llevaba las riendas de la FEUE desde 1975. Será para el 2010 con el boom del correismo que dicha organización salga de la federación, este cambio generó algunas expectativas, sin embargo no hubo mayores transformaciones. Una variación sustancial que se produjo fue el flujo presupuestario para la educación pública pero esto se

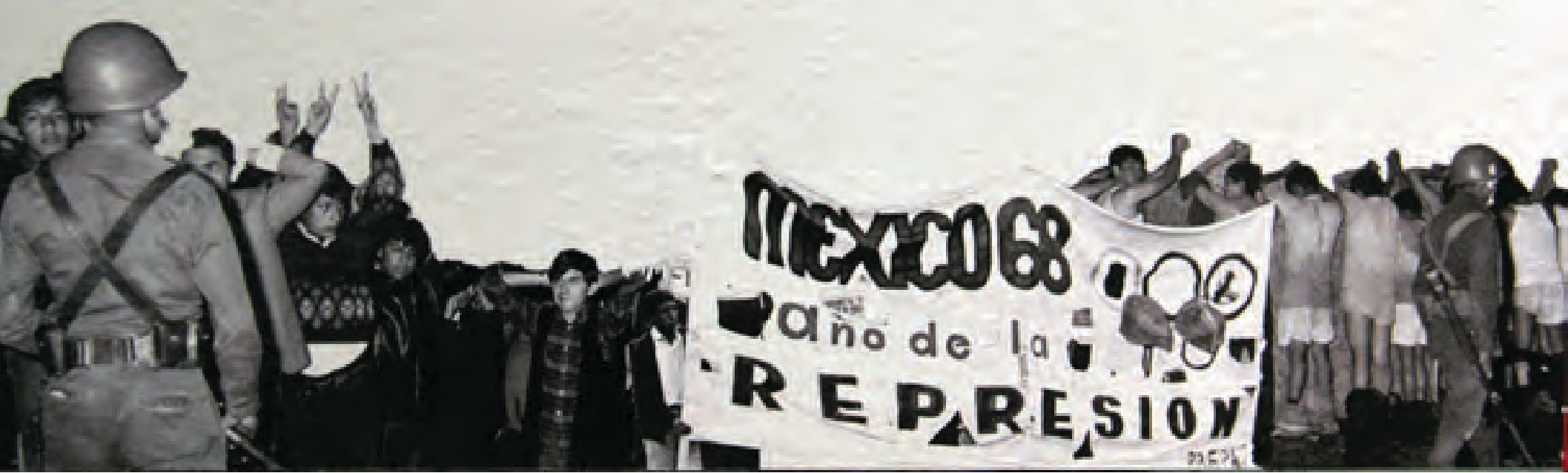


traducía en una menor autonomía de la UCE para con el Estado. Este ciclo se enmarca como de vacío propositivo y recuperación sin actores.

La histeria castrense en oposición de todo lo que suene a organización de izquierda se vio plenamente manifestada en la UBA con los asesinatos y desapariciones de muchos estudiantes, donde se desarticuló todo lo edificado hasta ese momento, el escaso activismo era microscópico por llamarlo de algún modo, la dictadura a su vez preparó las condiciones para la entrada del capital internacional.

Iniciados los años ochenta se va enfriando la beligerancia militar, lo cual de a poco facilitó la reestructuración y regreso de las organizaciones. La Franja Morada se hará de la dirección de la FUBA y las actividades en favor de los DD.HH coparán la agenda estudiantil. Para fines del decenio arriba Menem al ejecutivo y con él llega un tren de reformas neoliberales, los estudiantes se avocaron a movilizarse en defensa de la universidad pública y de a poco se desgastó la legitimidad con la que inició su mandato.

La agrupación Franja Morada erosionaba su legitimidad hasta perder la dirección de la FUBA, por otra parte las movilizaciones en contra del gobierno que a su vez era de la UCR iban en ascenso y se expresará en un profundo descontento social manifestado en asambleas, fábricas recuperadas, piquetes y, tendrán en constante movilización al país hasta mediados del 2002.

Mientras la reconvertida en izquierda tradicional estudiantil ligada al trotskismo y al maoísmo iba recuperando terreno a la par emergía una izquierda independiente ligada a los movimientos sociales y pugnando por una estructura horizontal, así la problemática del sentido de lo estudiantil y de los modos de lo político serán parte de su debate, quienes a su vez alternaban, se aliaban o conflictuaban con la izquierda partidista.

La llegada del kirchnerismo significó la disminución de la conflictividad de manera temporal y se dará a la tarea de reinstitucionalizar el país quien además se montó sobre el proceso previo de politización para llevarlo adelante. Los estudiantes por su lado se movilizaron por presupuesto u oponiéndose a la evaluación académica. También se da un crecimiento de las organizaciones afines al gobierno fuertemente apoyadas por este.
Desde el año 2010 se da una alternancia y coexistencia en la FUBA entre trotskismo, izquierda independiente reconvertida en izquierda popular y peronismo con una tendencia a generarse bloques entre estos y sus grupos afines. Para el año 2015 la llegada de Macri y su impronta neoliberal avizoran un resurgir del activismo. Este proceso cuenta con tres momentos: el primero que sería de desaparición, el segundo de recuperación y el tercero de fortalecimiento.

Antes de pasar a hacer una interpretación de lo que ocurrió en los años ochenta queda preguntarse ¿qué pasó en la UNAM? Como se pudo observar, los periodos propuestos solo concuerdan con los años de conformación, mientras que en los de expansión si bien son relativamente similares estos se dieron con signo político distinto y ligándose al régimen. En cambio los años de radicalización fueron más apresurados y reprimidos cortando la posibilidad de una fase insurreccional amplia y restringiéndola a espacios acotados como la misma UNAM o en relación con otros sectores sociales.

¿A qué pudo deberse? Se tiene que la revolución mexicana, marcó un giro muy temprano en el tipo de régimen, a esto se suma que mientras se estabilizaba debido a las continuas confrontaciones entre grupos armados, solidificó un estilo autoritario para poder sostenerse, además se estableció un partido oficial que se mantuvo a lo largo del tiempo.

Se agrega el hecho de que en buena medida la izquierda era cercana a los sectores oficiales durante buen tiempo y su influencia en una universidad conservadora causó un efecto más bien contraproducente en el estudiantado. En ese vaivén entre gobierno progresista autoritario e institución educadora, los consensos se alcanzaron de modo distinto, por tanto la autonomía tuvo un matiz diferente al del resto del continente, pues sirvió para consagrar a la libertad académica en contradicción con el socialismo educativo que se intentaba implantar para ese momento.

La ley de 1945 produjo una distancia insalvable entre autoridades y estudiantado, lo cual tuvo como efecto lograr manejar a una reducida pero influyente élite universitaria. Los estudiantes en primera instancia opuestos mayoritariamente a los diferentes gobiernos, luego se dieron a la tarea de respaldar a sus autoridades quienes adquirieron un carácter de 
resistencia frente al régimen que solo cesó después de 1945, pasando a darse una mayor interpenetración entre Estado y universidad, pero dicha ley dejaba marginados sustancialmente a los estudiantes del gobierno universitario, ya que en buena medida se fraguó para erradicar a la política de la UNAM.

En los años venideros los gobiernos prodigaron un presupuesto cuantioso a la entidad, esto resaltaba su condición de beneficiarios del régimen, a su vez el Partido Revolucionario Institucional -PRI- se dio a la tarea de buscar en la institución sus cuadros políticos y a fagocitar los entes federados, como lo intentaba hacer en el resto de gremios. Es decir, la hipotética respuesta apunta a afirmar que un Estado que iba a contracorriente del resto de los regímenes en el continente, produjo temporalmente un estudiantado que a su vez iba a contracorriente del régimen, generando un sentido inverso al del resto del estudiantado en relación a otros países.

\section{Las organizaciones estudiantiles al tener un arraigo sobre todo moderno y estar inmersos en una politicidad de base clasista les ha costado adaptarse al cambio de paradigmas y remarcan un tipo de accionar que se relaciona con las instituciones en las que se insertan, asi como el hecho de que su evolución sea más lenta que lo que ocurre con los diferentes procesos politicos.}

\section{Una interpretación posible}

A lo largo de casi todo el siglo veinte las organizaciones y los movimientos estudiantiles respondieron de manera casi concomitante a los diferentes momentos políticos, pero este accionar en algunos casos se fue apartando de los procesos políticos considerados relevantes para cada país a partir de los años ochenta. ¿A qué se pudo deber? El hecho de estar inmersos en una realidad poliédrica y multifactorial con sus líneas de fuerza y correas de transmisión en las que intervienen varias instituciones hace que los estudiantes se desenvuelvan ante un entorno específico con sus especificidades.

En el transcurso de la centuria estos se inscribieron en un tipo de institución que proclamaba la modernidad, el desarrollo y la ciencia como la razón de ser de la construcción del Estado-Nación y los estudiantes se enarbolaron como actores paradigmáticos de la modernidad periférica sigloventina, eso explica su oscilación en concordancia con los distintos momentos políticos hasta los años ochenta, pero al producirse un desplazamiento de la matriz estadocéntrica hacia otra con Estado reducido y los estudiantes al estar articulados en relación con y contra el Estado se produjo una pérdida temporal de sentido en su accionar.

A lo anterior se suma la crisis de la izquierda partidaria con base clasista perdiendo su radicalidad significacional ${ }^{2}$, dándose además una alteración en la discursividad, es decir, la idea de toma del poder entendida como toma del Estado a partir de la revolución también se descentró, pues esa noción de poder se vio comprometida por su carácter moderno y se pasó a entender como resistencia, desafección o a la posibilidad de construcción de poder autónomo.

En este recorrido de los ciclos organizativos, se observa cómo lo político se desplaza e intenta dejar atrás aquellas estructuras anquilosadas para restituirlas por otras efectivas y aglutinadoras que permitan una mayor movilización de voluntades. No obstante, este ingente esfuerzo de politización terminó siendo duramente reprimido en muchos casos, para que lo político organizativo se desgaste y traslade a lugares menos públicos, pasando a configurarse una alternancia entre lo íntimo, lo estético y lo expresivo en lo que a maneras de desenvolvimiento estudiantil se refiere.

De forma paralela se dio un desplazamiento de la politicidad hacia otros actores sociales en las que los estudiantes podían seguir participando pero su actuación como movimiento estudiantil dejaba de ser protagónico al quedar inscritos en una mirada tanto más ambigua y abarcante sobre lo juvenil. A lo anterior se adhieren los posicionamientos sobre la pluriculturalidad y territorialidad, las opciones e identidades sexuales, el derecho al aborto, las posturas ecologistas y otras. Se puede afirmar que en conjunto pasaban a formar parte 
de las resistencias, produciéndose una politización de la cultura así como una estetización de la política.

Junto con lo anterior operó también una metamorfosis expresada en el descreimiento de la política tradicional y con ello se produjo un lento cambio de los soportes organizativos que se adecuaron a las realidades de cada contexto.

Además, la identificación del con quiénes y contra quiénes se enmarca en procesos de lucha y enfrentamiento social de lo que se identifica como el poder o el enemigo en determinado momento, mismo que tiene una historicidad y debido a ello ciertas constantes y variaciones. Lo propio ocurre al establecer posibles aliados, estos también varían en función de los objetivos, el despliegue de fuerzas y el grado de organización.

Las organizaciones estudiantiles al tener un arraigo sobre todo moderno y estar inmersos en una politicidad de base clasista les ha costado adaptarse al cambio de paradigmas y remarcan un tipo de accionar que se relaciona con las instituciones en las que se insertan, así como el hecho de que su evolución sea más lenta que lo que ocurre con los diferentes procesos políticos.

Esa dinámica de adaptación diferenciada ha hecho que las organizaciones pasen por diferentes reacomodos y en varios casos aún no lo han conseguido como es el caso de la USAC y la UCE, en menor medida la UNAM; la UNAN, en cambio, teniendo un gran periodo de activismo en la década de los ochenta y de resistencia en los noventa, luego se cayó en el burocratismo, desinterés y aversión por la mayoría estudiantil.

Las organizaciones estudiantiles evolucionaron más lentamente que las luchas sociales y sin decir que se hayan quedado sin vasos comunicantes entre sí, el eje dejó de ser temporalmente la politicidad de base clasista, con ello los movimientos estudiantiles perdieron su centralidad, teniendo que adaptarse con lo que tenían a mano para reconstituirse cuando lo pudieron hacer.

Si las maneras de organizarse se estructuran en función del entorno, también adoptan la manera histórica que en ese proceso prevalezca, ya sean clubes, partidos, frentes, células, bloques, asambleas, colectivos o redes. Puede decirse que estos son modelos preponderantes para un periodo histórico y no para otros, eso no quiere decir que no se combinen en determinados momentos, correspondiéndose con los distintos

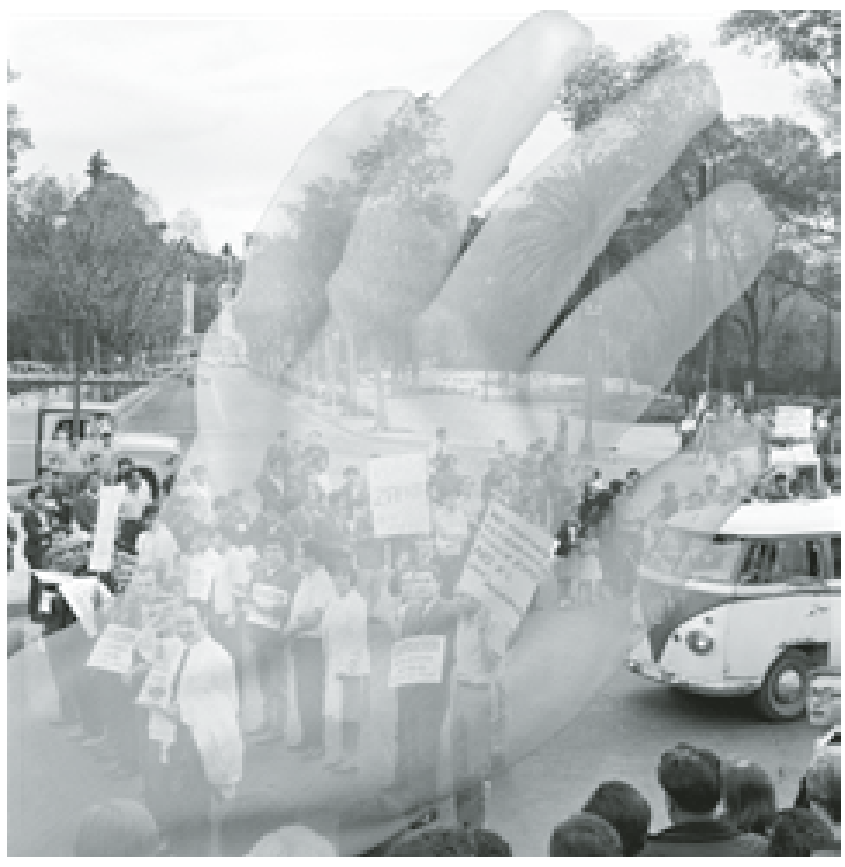

Karina Perdomo (Uruguay), Sin título, fotografía intervenida, 2018 (detalle tríptico) Archivo Histórico de la UNAM / IISUE-AHUNAM 
sentidos de época y los procesos de maduración en la politicidad por parte de los estudiantes.

A lo cual se suma la respuesta que planteen los regímenes instituidos en relación con la construcción que se haga del enemigo interno, a través de los distintos tipos de gobierno ya sean conservadores, liberales, caudillistas, oligárquicos, dictaduras militares y civiles, democrático progresistas y neoliberales, revolucionarios o contrarrevolucionarios, populistas tecnocráticos, etc., esto también incide en las maneras de organizarse y que metamorfoseen concomitantemente con el tipo de enfrentamiento que se imprima.

Sin olvidar que guardan relación con la presencia de partidos políticos, sindicatos y movimientos, que inciden en los modos de articularse, así como en otros momentos pueden imponer sus propias visiones de la manera en que debe operar el colectivo.

Se resalta que la casi totalidad de movilizaciones o despliegues organizativos oscilan entre la conflictividad contra políticas generadas desde los gobiernos de turno y las producidas al calor de oponerse a determinadas variaciones en el régimen universitario, sea por los tipos de autoridad ejercida o intentando revocar alguna disposición académica considerada perjudicial para el común del estudiantado. Buena parte de los conflictos se produjeron por motivos internos universitarios, aunque en ocasiones sirvieran para propagarse contra la situación política en general.

Aunque su historia no puede explicarse por fuera de la evolución de los partidos políticos y supeditados a estos durante buena parte del siglo, su desenvolvimiento no es similar ni tampoco sus ritmos organizativos, esto se debe al hecho de moverse al interior del sistema universitario con sus maneras permitidas o exigidas de participación se manejan con otros requerimientos y temporalidades, además de su alta rotatividad.

Los cambios en las formas organizativas operan en periodos que preceden y suceden aunque por lapsos relativamente cortos a los modelos y funciones de los distintos tipos de régimen; sin embargo, estos marcan una pauta de transformación paulatina o las modelan en el mediano plazo, ligados con el sentido de época al que también ayudan a establecer. No obstante, la conflictividad se trasladó hacia lugares diferentes transformando a su vez al sentido de época, dejando luego de los años ochenta a la mayoría de organiza- ciones estudiantiles sin referentes a los cuales asirse y debiendo modificarlos para reorganizar su legitimidad sin que necesariamente ocurra, dedicándose en algunos casos a exigir la no reducción de derechos o bienestar universitario.

Durante la primera década del nuevo siglo en varios países se dio una recuperación del Estado con el respectivo refinanciamiento a las universidades, sin embargo, en algunos casos los estudiantes no participaron o son francamente contrarios a este accionar progresista como ocurrió en la UCE en la que una mayoría no es afín pero están poco organizados y los organizados en contra tienen escasa legitimidad, a su vez los organizados a favor del régimen no tienen proyecto aunque hayan logrado insertarse en la FEUE, decantando en un quemimportismo generalizado.

Caso contrario en la UNEN sí se da una correspondencia entre dirigencias y proyecto de gobierno sin tener en cambio mayor relación con el estudiantado a menos que sea por beneficios concretos. En la UBA sí se tuvieron procesos organizativos que precedían al kirchnerismo y donde parte de la organización estudiantil se le oponía, también hubo intentos por parte del gobierno por entrar a disputar los espacios estudiantiles con escaso éxito al interior de la UBA pero no así en otras universidades del país.

Por otro lado, gobiernos reaccionarios o neoliberales no tienen un correlato necesario de mayor respuesta estudiantil o la misma es intermitente frente a embates concretos como en México. Claro que este no fue el caso colombiano donde estudiantes de todo el país se movilizaron para impedir una mayor privatización, en Chile pese a todo el despliegue de movilizaciones y organización estudiantil no se pudieron revertir sustancialmente leyes privatistas que vienen desde la dictadura pinochetista. En Guatemala a gobiernos lumpenizados les ha correspondido federaciones de igual índole, lo cual significa una subsunción de lo organizativo a lo político general.

Del proyecto de cambio social radical emancipatorio frente a los distintos regímenes se pasó a los movimientos de contención que intentan impedir la avanzada privatizadora y a conflictos más acotados. En común se tuvo la arremetida neoliberal y el abandono presupuestario, pero las organizaciones estudiantiles no reaccionaron de la misma manera, dependiendo 
de su estado de fuerzas y de la posibilidad de levantar oposición a los intentos de aplicación de políticas eficientistas o privatizadoras.

Se abre la duda sobre ¿por qué en algunos países hubo una recuperación de los movimientos estudiantiles universitarios y en otros no?, una respuesta posible estaría en la mayor pregnancia de la politicidad de base clasista y las relaciones que de ella se desprenden, como sería el caso de Argentina, eso no quiere decir que en otras universidades no se pueda reactivar la contestatariedad, sino que su recuperación política puede estar atravesada por los clásicos móviles políticos como es el caso de Guatemala en que los estudiantes se levantaron por las irregularidades en el manejo del gobierno, inmersos eso sí en movilizaciones más amplias o en clave ciudadana, o ser intermitentes como ha sido en México en los últimos treinta y cinco años.

La base clasista está atravesada por una menor pérdida de legitimidad en cuanto a los partidos de izquierda tradicionales así como de la organización universitaria en términos federativos, esto de algún modo da cuenta del tipo de relacionamiento entre instituciones como el Estado, los partidos y la universidad, a la par que el entendimiento y legitimidad que de ellas emana en relación con las agrupaciones y con el estudiantado que son quienes en últimas permiten que estos existan y se mantengan.

En la UBA la federación se estructura de acuerdo a las maneras de organizarse si se quiere clásicas con sus jerarquías y contrapesos, en cambio las organizaciones estudiantiles lo efectúan en un amplio espectro que va desde el centralismo democrático, pasando por el asambleísmo coordinado hasta llegar al espontaneismo microgrupal, cada uno con diferentes ventajas y límites.

\section{Activismo, organización y federaciones ¿qué relación guardan?}

Es preciso destacar que la relación entre federaciones y estado organizativo o de movilización estudiantil tampoco es mecánica y si bien puede servir como medidor de legitimidad habría que acotarlo a cada contexto. Tal es el caso de la UNAM que abandonó ese tipo de organización hace cincuenta años, por el contrario en la UBA, lo que ocurre en la FUBA si es un medidor ...la casi totalidad de movilizaciones

o despliegues organizativos oscilan entre la conflictividad contra politicas generadas desde los gobiernos de turno y las producidas al calor de oponerse a determinadas variaciones en el régimen universitario, sea por los tipos de autoridad ejercida o intentando revocar alguna disposición académica considerada perjudicial para el común del estudiantado.

del estado de fuerzas en juego al interior de la institución lo que no ocurre con la Federación Universitaria Argentina -FUA- que es el gremio nacional, que para algunos consiste en un "sello de goma" aludiendo a que no representa al estudiantado pero sirve para acceder a determinados espacios de gestión en las diferentes universidades.

Algo parecido ocurre con la AEU y la FEUE quienes operan alrededor del gobierno universitario pero sin mayor reconocimiento entre el estudiantado, eso no demerita el hecho que de cuando en cuando diversos colectivos traten de hacerse de estas instancias con el afán de cambiar la correlación de fuerzas, darles mayor beligerancia o pretender desde ahí impulsar el activismo estudiantil.

Tanto la AEU como la UNEN han servido para contener y hasta reprimir a quienes se oponen ya sea a rectorado como al régimen, en estos casos las federaciones pasan por el grado de legitimidad que les otorga el estudiantado y su validación pasa por hacerse de ellas, desconocerlas o enfrentarlas abiertamente de modo espontáneo u organizándose por fuera de lo gremial universitario. 
Aunque pueda darse por sobreentendido, el activismo guarda una relación fuerte con el estado organizativo estudiantil, federativo o no; ya que al haber organizaciones sostenidas, actividades permanentes, así sea sin movilizaciones pero de continuo accionar, es más factible que ante periodos de conflictividad estas tengan mayor poder de respuesta en cuanto a convocatoria y movilización.

\section{A cien años de la revuelta de Córdoba se puede observar que la movilización estudiantil en términos generales pasa actualmente por un momento de inflexión o repliegue a diferencia de lo que ocurrió hace cincuenta años en 1968 cuando se atravesaba por un gran periodo de insurrección y despliegue.}

A eso se suma la interrelación con otros grupos o movimientos, ya que estos pueden generar un mayor alcance en cuanto alianzas o acciones conjuntas, que por el contrario cuando estallan espontáneamente acciones de indignación pero existe un estado latente, pasivo o apático del estudiantado las movilizaciones pueden ser de gran impacto pero de poca sostenibilidad en el tiempo y probablemente de escasos logros en cuanto a cumplimiento de demandas, también puede haber organización estudiantil sin que haya movimiento, sobre todo cuando estos no tienen legitimidad.

Un movimiento estudiantil se estructura cuando opera una combinación de formas organizativas e individuos y un mínimo de articulación entre ellas, siendo el desenlace de la movilización política del estudiantado la que decante en una presencia masiva de estos con sus diferentes maneras de accionar, dando cuenta de los múltiples modos de organizarse. De ese modo un movimiento estudiantil oscila "entre un grado máximo de desestructuración, en la cual se ubican las acciones inorgánicas y espontáneas, a un grado máximo de estructuración, donde la acción es llevada a cabo orgánicamente por instancias altamente institucionalizadas" (Pronko, 1999: 241-242), formando parte de un proceso donde están en permanente tensión ambos extremos del continuo, afirmará la misma Pronko. A eso se debe sumar los canales de transmisión política, el grado de legitimidad entre colectivos y estudiantado, las alianzas con otros sectores organizados, así como entre el grueso del alumnado y el resto de la sociedad.

\section{Palabras finales}

Los estados de fuerza organizacionales guardan mayor relación con el ambiente de época imperante que con el tipo de régimen político vigente, pues las formas organizativas estudiantiles tienen una evolución más lenta y hasta cierto punto independiente de los gobiernos de turno, aunque no de los bloques temporales por lo menos hasta los años ochenta, guardando cierta consonancia con el estado organizativo y de movilización general de la sociedad hacia esos años.

La interdependencia tanto entre agrupaciones estudiantiles del mismo país como con las de otros países a la vez que con las organizaciones políticas, provocó el que se retroalimentaran mutuamente, así como las condiciones sociales y políticas de cada país y universidad los vuelve a la vez singulares y distintos, en esa medida es el espíritu de época imperante el que en buena parte hará que muten o no las formas organizativas estudiantiles.

A la par que las formas organizativas preponderantes al parecer se ralentizan o aceleran dependiendo de una multiplicidad de factores que tienen que ver con el grado de politización producido tanto al interior de las mismas organizaciones como de la politicidad existente en el entorno en que se desenvuelven.

Dichos ciclos propios de organización estudiantil solo quedan parcialmente explicados si no se toma en cuenta su condición universitaria quien es la que le otorga su dimensión específica en cuanto a espacio del conocimiento y caja de resonancia, el hecho de compartir un lugar físico y los tiempos de clases, exámenes y vacaciones, además de la alta rotatividad del estudiantado.

Todo eso permite en conjunto explicar cómo operan esos procesos de ascendencia, consolidación, 
radicalización, insurrección y su posterior dividirse hacia diferentes derroteros histórico-organizacionales llámese de activismo intermitente, persecución y desaparición, lumpenización, revolución y resistencia, anquilosamiento y burocratización, vacío propositivo, recuperación o fortalecimiento. Procesos diferentes en su mayoría que explican lo ocurrido a partir de los años ochenta.

De ahí el interés en indagar en la dimensión política que existe en las organizaciones, esa voluntad terca por persistir y organizarse muchas veces a espaldas de las formas esperadas para una época, generación o modelo a seguir, donde la politicidad muta y se resignifica en otras maneras de organizarse, aunado a la intención de los regímenes discursivos hegemónicos por tratar de desmontar la politicidad estudiantil.

Este texto trató de observar esas constantes cíclicas y sus posteriores desencuentros en relación con las formas organizativas estudiantiles universitarias y sus transformaciones a lo largo del tiempo. La idea fue comprender dichas variaciones en la correlación de fuerzas con respecto a quienes se enfrentaban y como estos a su vez trastocaron su modo de proceder. A la vez que se resaltó su centralidad o pérdida de protagonismo a lo largo de este periplo y cómo se decantaron en las diferentes luchas históricas.

A cien años de la revuelta de Córdoba se puede observar que la movilización estudiantil en términos generales pasa actualmente por un momento de inflexión o repliegue a diferencia de lo que ocurrió hace cincuenta años en 1968 cuando se atravesaba por un gran periodo de insurrección y despliegue. Si se toma en cuenta lo planteado en la ciudad de Córdoba en su ya centenaria revuelta de 1918 en lo que tiene que ver con autonomía, libre ingreso, libre asistencia, libertad de cátedra, extensión universitaria y cogobierno/ gobierno paritario, se tiene que a buena parte de las universidades del continente todavía les falta un largo trecho por recorrer, aunque queda preguntarse si estas demandas aún son necesarias actualmente y no está de más afirmar que sí, pero llevarlas a cabo conlleva un cambio profundo en las estructuras sociales, lo cual hace que estas reivindicaciones aparentemente gremiales o intrínsecas a lo universitario se conviertan en exigencias políticas que atañen al conjunto de la sociedad. 


\section{Notas}

1. La mayoría de las instituciones abordadas cambiaron de nombre en más de una ocasión a lo largo del siglo XX, lo cual ya de por sí posee una rica historicidad, sin embargo, para efectos del texto se emplean los nombres actuales para evitar confusiones.

2. Dicha pérdida no fue inocente ni se dio de la noche a la mañana, ya que atravesó un largo proceso que abarcó asesinatos y persecuciones por un lado y por otro se dio una agresiva reducción del estado, pérdida de derechos laborales, así como de soberanía al permitir el ingreso de conglomerados transnacionales, además hubo un arrinconamiento del marxismo en múltiples espacios, seguido de un desprestigio de lo público, a la par que un encantamiento del éxito individual.

\section{Bibliografía}

Adorno, Theodor. (1970) "Concepto de iluminismo", en Dialéctica del iluminismo. Editorial SUR, Buenos Aires.

Álvarez Aragón, Virgilio. (2002a) "Conventos, aulas y trincheras: Universidad y movimiento estudiantil”, en Guatemala: la ilusión por conservar. Volumen I. FLACSO-G. USAC, Instituto de Investigaciones Históricas, Antropológicas y Arqueológicas. Guatemala.

(2002b) "Conventos, aulas y trincheras: Universidad y movimiento estudiantil”, en Guatemala: la ilusión por conservar. Volumen II. FLACSO-G. USAC, Instituto de Investigaciones Históricas, Antropológicas y Arqueológicas. Guatemala.

Álvarez Mendiola, Germán. (1985) "El movimiento estudiantil en la UNAM en la década setenta". Tesis de Licenciatura en Sociología. UNAMFCPyS. México.

Baltodano, Mónica. (2011) Memorias de la lucha Sandinista. De la forja de la vanguardia a la montaña. Fundación Rosa Luxemburgo, Managua, pp. 1-20.

Bonavena, Pablo; Califa, Juan Sebastián y Millán, Mariano (Comp.). (2007) El movimiento estudiantil argentino. Historias con presente. Edición Cooperativas. Buenos Aires.

Bonavena, Pablo; Millán, Mariano. (2012) "El movimiento estudiantil en la actualidad argentina: una aproximación sociohistórica”, en OSAL. CLACSO, año XIII, núm. 31, mayo. Buenos Aires, pp. 105-122.

Califa, Juan Sebastián. (2014) Reforma y revolución: la radicalización política del movimiento estudiantil de la UBA 1943-1966. Eudeba. Universidad de Buenos Aires. Buenos Aires.

Castoriadis, Cornelius. (1989) La institución imaginaria de la sociedad. Vol. 2: El imaginario social y la institución, Tusquets Editores, Barcelona.

Celi, Carlos; Moreno, Kintia. (2017) "Construcción de la negatividad: Universidad Central del Ecuador y Movimiento Estudiantil a los ojos de diario El Comercio (1980-1996)", en Movimientos estudiantiles en la historia de América Latina V. Coord. Renate Marsiske. IISUEUNAM. México.

Chavarría, Sebastián. (2011) "Nicaragua: Restauración, bonapartismo y lucha política”, en 1857. Revista Centroamericana de Teoría, Política, Economía e historia. núm, 11. Septiembre-Diciembre. Disponible en: https://elsoca.org/pdf/Revista-1857-No-11.pdf

Chávez Becker, Carlos. (2004) Estudio y análisis comparativo sobre los movimientos estudiantiles en la UNAM en 1986-1987 y 1999-2000. Tesis de licenciatura en ciencia política. UNAM. México D.F.

CMI. (2015) De Oliverio a Isla de Gilligan. Cómo fue cooptada la AEU. 23 de septiembre de 2015. Disponible en https://web.archive.org/ web/20151016233053/https://cmiguate.org/de-aeu-a-isla-degilligan-como-fue cooptada-la-asociacion-de-estudiantes/

Córdoba, Matilde. (2007-Noviembre-05) César Pérez y los mitos de la UNEN. Disponible en https://www.elnuevodiario.com.ni/politica/1688cesar-perez-mitos-unen/

Cristal, Yann. (2012) "Historia reciente del movimiento estudiantil de la UBA (1982-2011)”, en IV Jornadas de Estudio y Reflexión sobre el Movimiento Estudiantil Argentino y Latinoamericano. Universidad Nacional de Luján, Buenos Aires, pp. 1-17.

Domínguez, Raúl. (1989) "El perfil político de las organizaciones estudiantiles durante la década de 1950", en Los estudiantes. Trabajos de historia y sociología. Coord. Renate Marsiske. UNAM-CESU, México, pp. 261-290.

Duverger, Maurice. (2012) Los partidos políticos. Fondo de cultura económica. México D.F.

Echeverría, Bolívar. (1995) "Las ilusiones de la modernidad. Ensayos" en El equilibrista. UNAM. México.

Estrello, Luz; Modonesi, Massimo. (2012) “El \#YoSoy132 y las elecciones en México. Instantáneas de una imposición anunciada y del movimiento que la desafió." en OSAL. CLACSO. año XIII, num. 32. noviembre. Buenos Aires, pp. 219-242.

Fernández, Paula. (2013) "La fractura del movimiento revolucionario: tendencias dentro del Frente Sandinista de Liberación Nacional (1972-1979)", en Cuadernos de Marte. año 3. num. 4, julio. Buenos Aires, pp. 150-185. Disponible en http://iigg.sociales.uba.ar/revistacuadernosdemarte

Fernández, Joseba; Sevilla, Carlos; Urbán, Miguel. (2013) "La Universidad como campo de batalla de la lucha de clases,” en Fernández González, Joseba; Urbán Crespo, Miguel; Sevilla Alonso, Carlos. (Coords.) De la nueva miseria. La universidad en crisis y la nueva rebelión estudiantil Ediciones Akal. Madrid, pp. 15-42.

Garretón, Manuel Antonio; Martínez, Javier: (1985) "El movimiento estudiantil: conceptos e historia." Tomo IV. Biblioteca del movimiento estudiantil. Ediciones Sur. Santiago de Chile.

Giroux, Henry. (1989) "La pedagogía de frontera en la era del posmodernismo", en De Alba, Alicia (Comp.) Posmodernidad y educación. UNAM-CESU. Porrúa editor. 2004, México, pp. 69-102.

Gómez Mendoza, Miguel Ángel; Álzate Piedrahita, María Victoria. (2010) "El 'oficio' de estudiante universitario: afiliación, aprendizaje y masificación de la Universidad," en Revista Pedagogía y Saberes No. 33. Universidad Pedagógica Nacional. Facultad de Educación. pp. 85-97. 
Harvey, David. (1998) La condición de la posmodernidad. Investigación sobre los orígenes del cambio cultural. [1990] Amorrortu editores. Buenos Aires.

López Castellanos, Nayar. (2013) Nicaragua, los avatares de una democracia pactada. UCA Publicaciones, Managua. Disponible en: http:// repositorio. uca. edu .ni/41/1/ Nicaragua_Avatares $\% 20$ de $\% 20$ una $\% 20$ democracia\% 20pactada. pdf

Marsiske, Renate. (2002) "Clases medias, universidades y movimientos estudiantiles en América Latina (1900-1930)”. en: Coord. Renate Marsiske. Movimientos estudiantiles en la historia de América Latina I. UNAM, CESU, Plaza y Valdés Editores, México D.F. pp. 142-157.

Martí I Puig, Salvador. (2016) "Nicaragua: Desdemocratización y caudillismo", en Revista de Ciencia Política. Vol. 36, núm. 1. Pontificia Universidad Católica de Chile, Santiago, pp. 239-258. Disponible en: http://www.redalyc.org/pdf/324/32446000011.pdf

Millán, Mariano. (2013) "Estudiantes y política en Argentina y Chile (19661973)", en Revista Izquierdas [en línea], núm. 16, agosto. Universidad Santiago de Chile, Santiago, pp. 31-54. Disponible en: <http://www. redalyc.org/articulo.oa?id=360133458002 $>$ ISSN

Mojica, Orson. (2014) Nicaragua (1979-1990): La revolución abortada. Libro Socialista. Centroamérica. Disponible: http://www.elsoca.org/pdf/ libreria/La\%20Revolucion\%20Abortada-lectura.pdf

Moreno, Kintia; Celi, Carlos. (2014) Representaciones en prensa sobre los movimientos estudiantiles en la Universidad Central del Ecuador. (1990-2013). Comité de Investigaciones UASB. Quito. Disponible en: http://repositorio.uasb.edu.ec/bitstream/10644/4488/1/201514-Celi-Representaciones\%20en.pdf.

Moreano, Alejandro. (2011) "Neoliberalismo, cultura y sociedad", en Nuestra América y el pensamiento crítico. Fragmentos de pensamiento crítico de Latinoamerica y el Caribe. Coord. Eduardo Grüner. CLACSO, Buenos Aires, pp. 143-185.

Ordorika, Imanol. (2006) La disputa por el campus. Poder, política y autonomía en la UNAM. UNAM-CESU. Plaza y Janes Editores, México.

Ortega Erreguerena, Joel. (2015) "Yo Soy 132: entre la red y las asambleas. Una rebelión con el autoritarismo", en Revista Pacarina del Sur (en línea). Movimientos juveniles en América Latina: Batallas e impugnaciones de la política, la educación y la cultura excluyentes. Año 6, núm. 25, octubre-diciembre. Dossier. Disponible en: www. pacarinadelsur.com

Pedrosa, Fernando. (1999) "La Universidad y los estudiantes frente a la dictadura militar", en Renate Marsiske (Coord.) Movimientos estudiantiles en la historia de América Latina II. UNAM, CESU, Plaza y Valdés Editores. México D.F. pp. 209-237.

Portantiero, Juan Carlos. (1978) Estudiantes y política en América Latina. 1918-1938. El proceso de la reforma universitaria. Siglo XXI. México D.F.
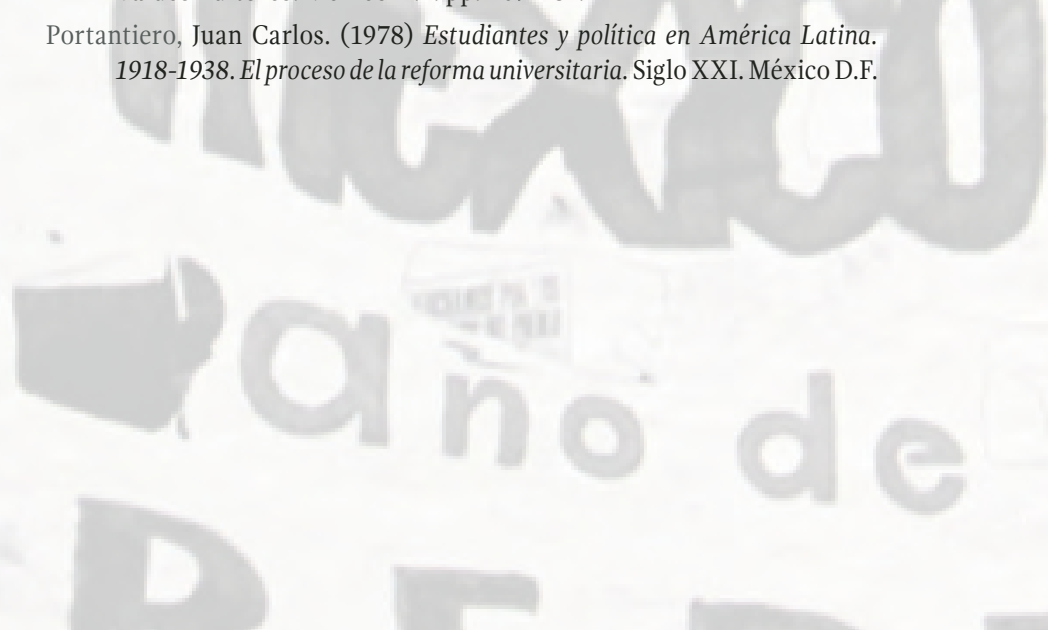

Rafael Agatti (Brasil), Sin título, fotografía intervenida, 2018 / Archivo Histórico de la UNAM / IISUE-AHUNAM
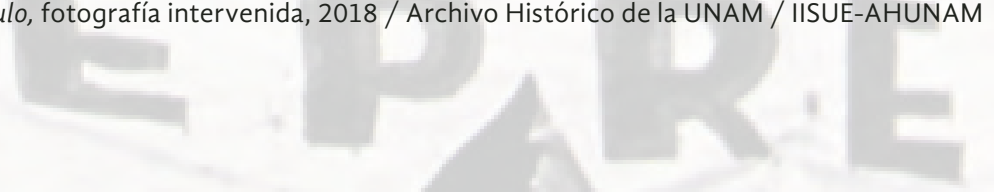
D.F. pp. 239-263. desencanto. Norma. Bogotá. México. Histórica). Abya-Yala. Quito. SENAJU, Lima, pp. 17-37. Central del Ecuador, Quito. campo. IEE-CDES, Quito, pp. 17-81. Managua, pp. 97-109. ar/art_revistas/pr.2814/pr. 2814. Pdf Gráficas Silva, Quito, Pp. 40-56.
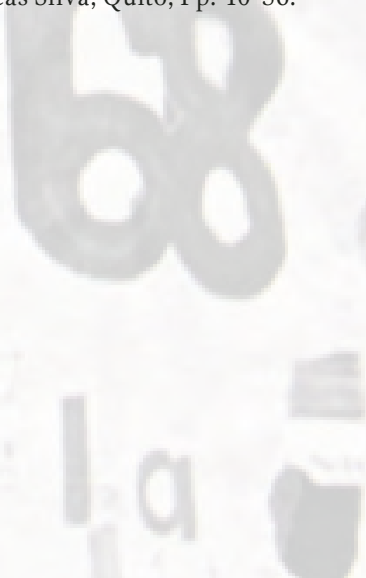
Renate Marsiske. (Coord.) Movimientos estudiantiles en la historia de América Latina II. UNAM-CESU, Plaza y Valdés Editores. México

Reguillo, Rossana. (2004) Emergencia de culturas juveniles. Estrategias del

Rivas Ontiveros, José. (2007) La izquierda estudiantil en la UNAM. Organizaciones, movilizaciones y liderazgos (1958-1972). Porrúa-UNAM.

Rodas, Germán. (2000) La Izquierda Ecuatoriana en el siglo 20. (Aproximación

Rodríguez, Ernesto. (2012) “Movimientos juveniles en América Latina: entre la tradición y la innovación”, en Movimientos juveniles en América Latina y el Caribe: entre la tradición y la innovación. UNESCO-CELAJU-

Romero, Ricardo. (1998) La lucha continúa. El movimiento estudiantil argentino en el siglo XX. FUBA. Eudeba. Buenos Aires.

Ruiz, Andrés. (2016) No todos los estudiantes son tan deahuevo: perspectiva crítica del movimiento estudiantil universitario. 30 de mayo 2016. Disponible en https://web.archive.org/web/20160601151553/ https://cmiguate.org/no-todos-los-estudiantes-son-tan-deahuevoperspectiva-critica-del-movimiento-estudiantil/

Sánchez, Paola. (2012) Discurso de ciudadanía: un acercamiento a las clases medias. Tesis para la obtención del título de Socióloga, Universidad

(2013) "Resistencia, consenso y disputa: conflicto social en el Ecuador (1990-2012)”, en Stalin Herrera (Comp.) ¿A quién le importan los Guayacanes? Acumulación, gobierno y conflictos en el

Traña, Marcia. (1990) "Algunas notas sobre el movimiento estudiantil nicaragüense en la primera etapa del siglo XX”, en Revista de Historia. Año 1, núm. 1, enero-junio, Instituto de Historia de Nicaragua-IHN-,

Tortti, María Cristina. (1999) “Izquierda y ‘nueva izquierda’ en la Argentina. El caso del Partido Comunista”, en Revista Sociohistórica, núm. 6, pp. 221-232. Disponible: http:/ /www.fuentesmemoria. fahce.unlp.edu.

Ycaza, Patricio. (2011) "Movimiento estudiantil universitario: de la rebelión a la incertidumbre", en Malaidea. Cuadernos de reflexión No. 2, noviembre. Universidad Pública y Movimiento Estudiantil. Artes
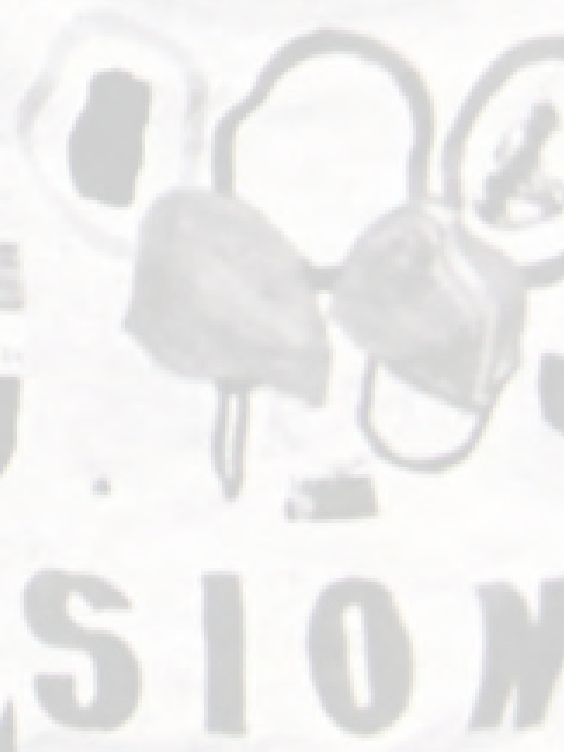